\title{
First Report on Cross-Infection of Coffee Leaf Spot Pathogen Myrothecium roridum on Black Pepper
}

\author{
A.P. Ranjini ${ }^{1 *}$, Madhu S. Giri ${ }^{1}$, S. Daivasikamani ${ }^{1}$, \\ Santoshreddy Machenahalli ${ }^{1}$, M. Sudha ${ }^{1}$ and Rajanaika ${ }^{2}$ \\ ${ }^{1}$ Central Coffee Research Institute, Coffee Research Station Post - 577117, \\ Chikkamagaluru District, Karnataka, India \\ ${ }^{2}$ Department of Applied Botany, Kuvempu University, Jnana Sahyadri, Shankaraghatta - \\ 577451, Shivamogga District, Karnataka, India \\ *Corresponding author
}

A B S T R A C T

Keywords

Black pepper,

Coffee, Cross-

infection, Leaf spot,

Myrothecium

Article Info

Accepted:

18 April 2019

Available Online:

10 May 2019
Myrothecium roridum, a fungal plant pathogen is known to infect the leaves and stem of coffee seedlings in the nursery and leaves and berries of the plants in the field. The pathogen has a very wide host base infecting many agricultural and horticulture crops, ornamentals, gymnosperms and weeds. As black pepper is a major intercrop grown in the coffee plantations, the present study was under taken to test the ability of $M$. roridum to infect black pepper (Piper nigrum L.). Two isolates of $M$. roridum, isolated both from coffee nursery and field was inoculated on the leaves of pepper vines. The results indicated that the coffee isolates of $M$. roridum could infect the leaves of the pepper vines. Two days after of inoculation, the pathogen expressed the symptoms on the inoculated leaves of pepper vines similar to that of Myrothecium leaf spot observed on coffee. The sporodochia could be observed on the inoculated pepper leaves on both lower and upper surface 8 days after inoculation and were arranged concentrically on the affected area. The artificial inoculation confirmed the ability of the pathogen $M$. roridum existing on coffee can infect the pepper vines and cause crop loss. As per our knowledge this is the first report of $M$. roridum found pathogenic on pepper vines.

\section{Introduction}

Coffee is a perennial plantation crop, cultivated in the tropics and sub-tropics of the world. The produce of coffee is internationally traded second to petroleum products and contributes about Rs.4,600 crores of foreign exchange to the national exchequer annually, apart from providing employment for more than 6 lakh people involved in the coffee industry (Anon., 2018). The roasted beans from fruits of the coffee plant are used mainly as a non-alcoholic beverage by several hundred million consumers throughout the world. The genus Coffea belongs to the economically important botanical family Rubiaceae. Arabica (Coffea arabica L.) and robusta (Coffea canephora 
Pierre ex Froehner) are the two major species of Coffea that are commercially cultivated in India (Wrigley, 1988; Anon., 2014; Ranjini et al., 2018).

The first record on infection of Myrothecium roridum on coffee plant was reported from Colombia in 1951 and Costa Rica in 1961 (Schier and Zentmyer, 1968). M. roridum is a cosmopolitan plant pathogen with wide host range causing leaf spot and necrosis on many agricultural crops such as cotton, tomato, cocao, coffee, potato, soybean, cucurbits as well as various ornamental plants (Preston, 1935; French, 1989; Yum and Park, 1990; Kim et al., 2003; Kyung et al., 2014). In India, the Myrothecium fungal infection on coffee was considered as minor disease in the past but in recent years the leaf spot and stem necrosis disease caused by Myrothecium on coffee is posing a major problem mainly during continuous rainy season (Daivasikamani et al., 2016). The disease is widely spreading in the coffee nurseries and field of Karnataka State and is observed on both the cultivated species of Coffea. The fungus infects foliage and stem of coffee seedlings in the nursery and the leaves of coffee plants in the field. Leaves and stem of coffee seedling infected with $M$. roridum initially show water soaked circular necrotic spots which gradually spread (Fig. 1 and 2). Black fruiting bodies are also noticed on the infected area (Fig. 3).

In India, coffee is mainly grown under shaded conditions with many intercrops like pepper, areca, cardamom, banana etc. Black pepper (Piper nigrum L.) is a major intercrop cultivated in most of the coffee growing areas. Cultivation of pepper in coffee plantation fetches an additional income to the farmer. As $M$. roridum is reported to have a wide host range, the present study was undertaken to find out the susceptibility of pepper vines by the pathogen $M$. roridum existing on coffee.

\section{Materials and Methods}

\section{Collection of samples}

The infected leaves showing typical leaf spot symptoms of Myrothecium roridum were collected from coffee seedlings and on coffee plants (Coffea arabica cv. Sln.13) both in the nursery and field of Central Coffee Research Institute (CCRI), Balehonnur situated at an elevation of 823-914 $\mathrm{m}$ above MSL and longitude $75^{\circ} 28^{1} \mathrm{E}$ and latitude $13^{\circ} 22^{1} \mathrm{~N}$ in Chikkamagaluru district of Karnataka State, India. The infected samples were thoroughly washed with running tap water and then immediately examined under a compound microscope for preliminary identification of the pathogen.

\section{Isolation of the fungus}

Isolation of the fungus was made by tissue isolation technique (Aneja, 2012). The coffee leaves exhibiting moderate to severe disease symptoms in the field and nursery were collected and cut into small bits with the help of a sterilized blade separately. Bits of diseased tissues were washed with sterilized distilled water and then disinfected with $1 \%$ sodium hypochlorite solution for two minutes followed by 2 to 3 thorough washing with sterilized water. The selected bits of diseased tissues both from nursery and field were transferred directly on the surface of potato dextrose agar containing Petri plates under aseptic conditions. Inoculated Petri plates were then incubated at $25{ }^{\circ} \mathrm{C}$. The resulting fungal cultures were purified after eight days of incubation by single spore isolation. The isolated fungus produced white buff colony on PDA medium with white flat mycelium producing concentrically arranged sporodochia (Fig. 4).

Morphological characters of the fungus were studied by Nikon SMZ-800 stereo-binocular and Nikon Eclipse E-600 research 
microscope. On the basis of morphological characters, the causal fungus was identified as Myrothecium roridum by comparing with the fungal culture collections maintained in the Division of Plant Pathology, CCRI.

\section{Pathogenicity test}

To test the pathogenicity of Myrothecium roridum isolated from infected coffee leaves on black pepper, the pepper vines which were grown in the CCRI farm was used for the study. The pathogenicity test was conducted by following mycelial disc inoculation method (Aneja, 2012). The surface of the pepper leaves to be inoculated was sterilized with $1 \%$ sodium hypochlorite with a cotton swab. Five mm culture disc from 10 days old pure culture of $M$. roridum was cut and placed on the lower surface of the leaves and similarly the coffee leaves were also inoculated with both the isolates of the pathogen as a standard check (Fig. $5 \& 6$ ). The leaves were covered with polypropylene bags for 48 hours to maintain humidity. Control plants were also maintained by placing plain agar disc on the pepper leaves. Observations at an interval of every 24 hours after inoculation was recorded up to 10 days by recording maximum and minimum temperature and for disease symptoms expression by the pathogen.

\section{Results and Discussion}

The average maximum and minimum temperature recorded during the experiment period was $27{ }^{\circ} \mathrm{C}$ and $12{ }^{\circ} \mathrm{C}$ respectively. Both the isolates of $M$. roridum obtained from coffee nursery and field were able to infect all the inoculated leaves of pepper vine and the symptoms expressed by the pathogen on pepper leaves are similar to that expressed on coffee. The un-inoculated leaves remained healthy. Two days after inoculation (DAI), the inoculated leaves of pepper (Piper nigrum L.) started exhibiting the symptoms similar to that of coffee with water soaked lesion around the inoculated site (Fig. 7). Greyish to dark brown lesions could be observed on 4 DAI (Fig. 8). The sporodochia could be observed on the inoculated pepper leaves on both lower and upper surface on 8 DAI and were arranged concentrically on the affected area (Fig. 9 and 11). Inoculated and infected leaves detached from the plant and defoliated on 10 DAI (Fig. 10)

The pathogen $M$. roridum was re-isolated from the inoculated and infected leaves of black pepper on PDA plates and the fungal colonies grown after incubation period was morphologically identical to the inoculated isolates of coffee, thus proving the Koch's postulates.

The studies of Mangandi et al., (2007) and Kim et al., (2003) revealed that regional change in the weather results in local growing conditions which is more favorable to $M$. roridum infection and also facilitates a broader host range for the fungus. On coffee, infection of $M$. roridum could be observed by Silva and Pinto in 2016 on Coffea canephora seedlings. Silvaldo et al., (2007) observed stem canker and leaf necrosis on coffee seedlings in Rio de Janerio state by $M$. roridum. From India, Nagaraj and George (1958) reported the Myrothecium disease observed on coffee seedlings as "Target leaf spot" disease. Further, he reported that the pathogen could infect the coffee plants and the berries under field conditions. Nirmala Kannan and Muthappa (1982) reported the Myrothecium disease as "Tip blight of coffee". $M$. roridum was recently reported as an endophyte of the gymnosperm, Pinus albicaulis at high elevation in Oregon (Worapong et. al., 2009). McLean and Sleeth (1961) from their studies reported that relatively high temperatures and frequent rain events are prerequisite for disease development. 


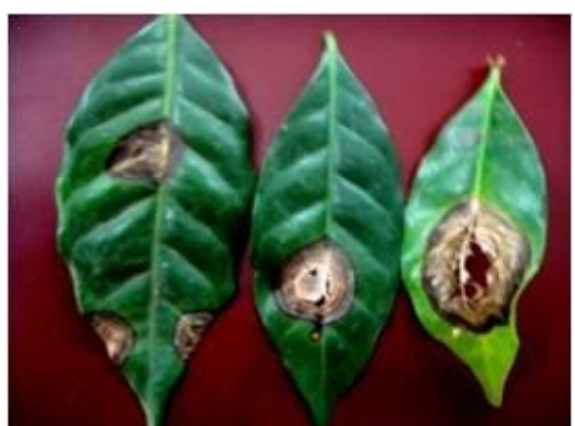

Fig.1 Myrothecium leaf spot on coffee leaves

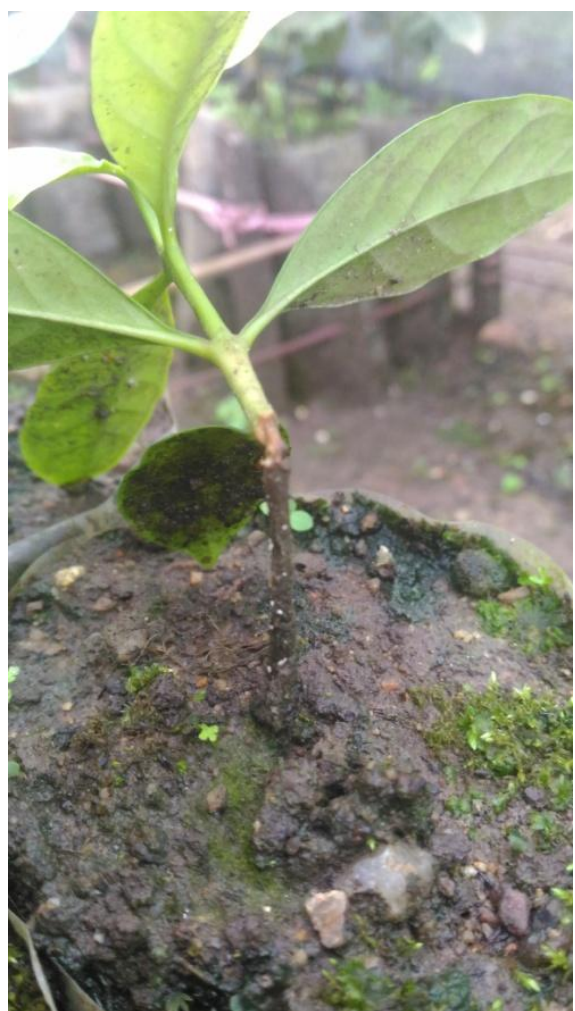

Fig.2 Stem necrosis on coffee seedling

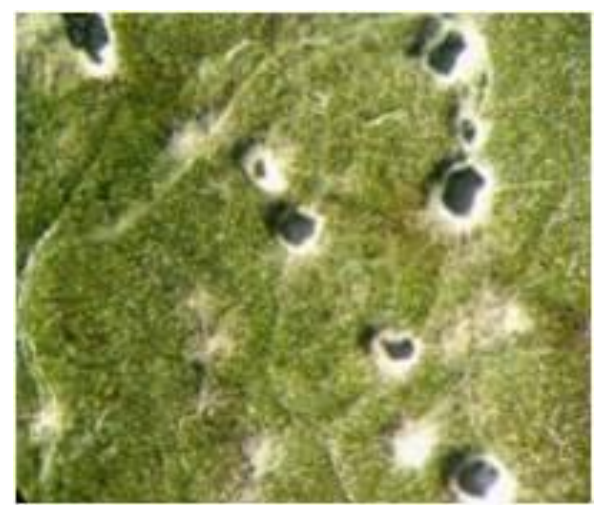

Fig.3 Microscopic view of Sporodochia on coffee leaves (20X) 
Int.J.Curr.Microbiol.App.Sci (2019) 8(5): 2245-2254

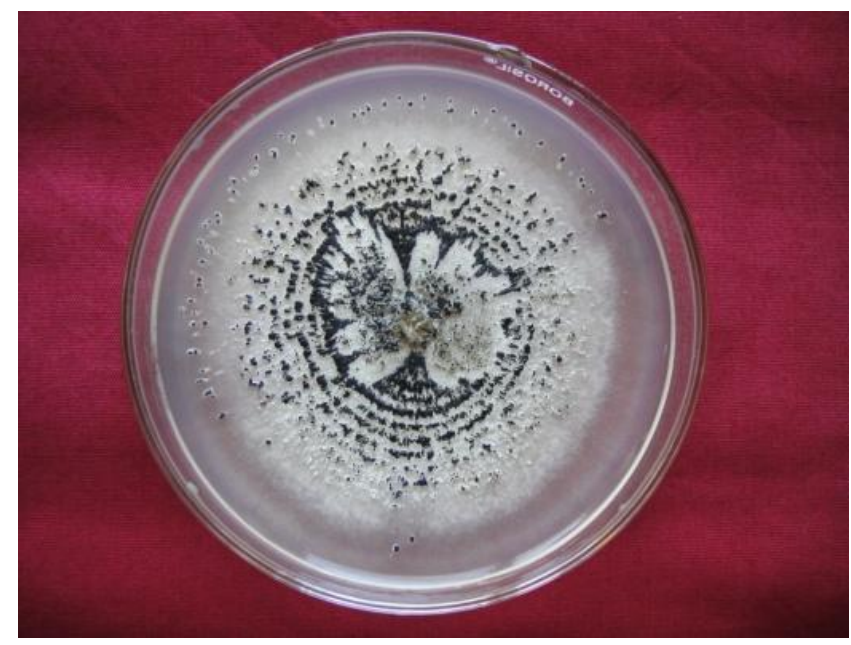

Fig.4 Axenic culture of $M$. roridum

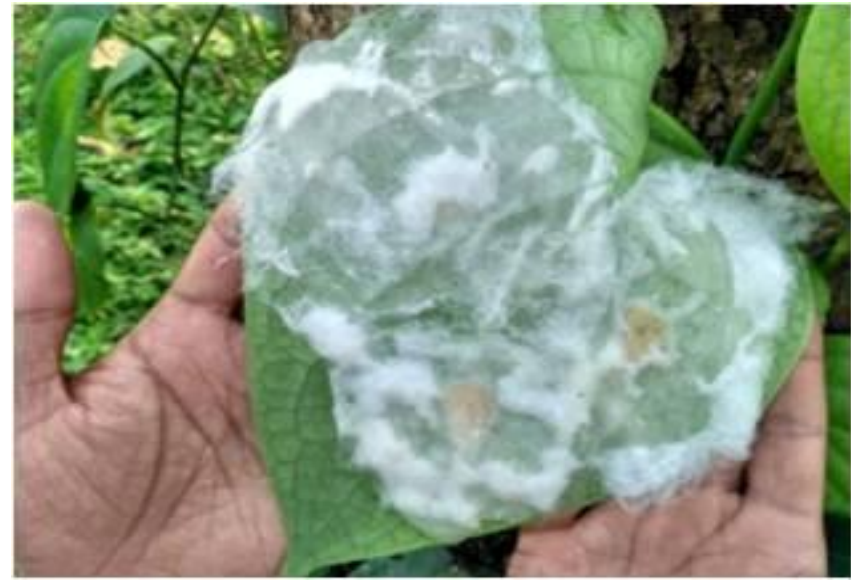

Fig.5 Inoculation on the pepper leaves

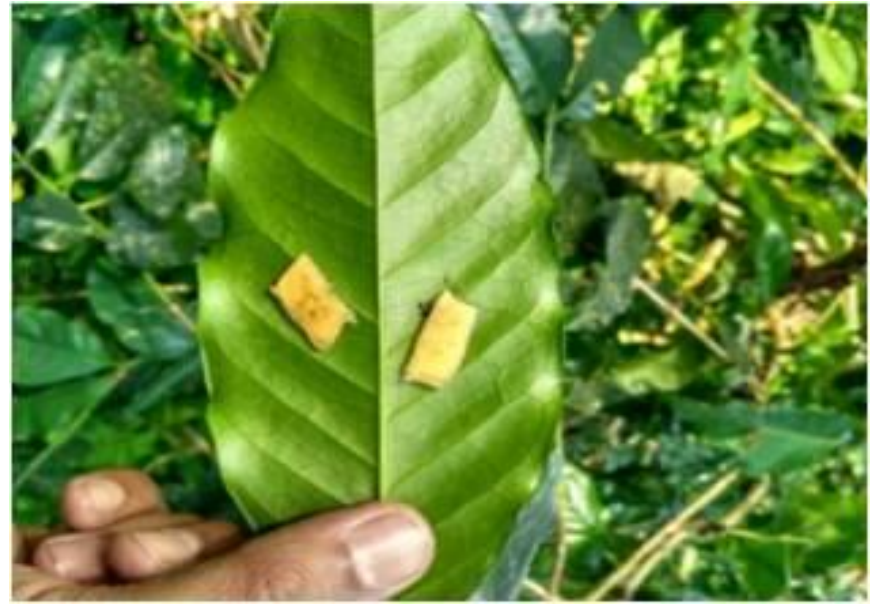

Fig.6 Inoculation on coffee leaves 
Int.J.Curr.Microbiol.App.Sci (2019) 8(5): 2245-2254

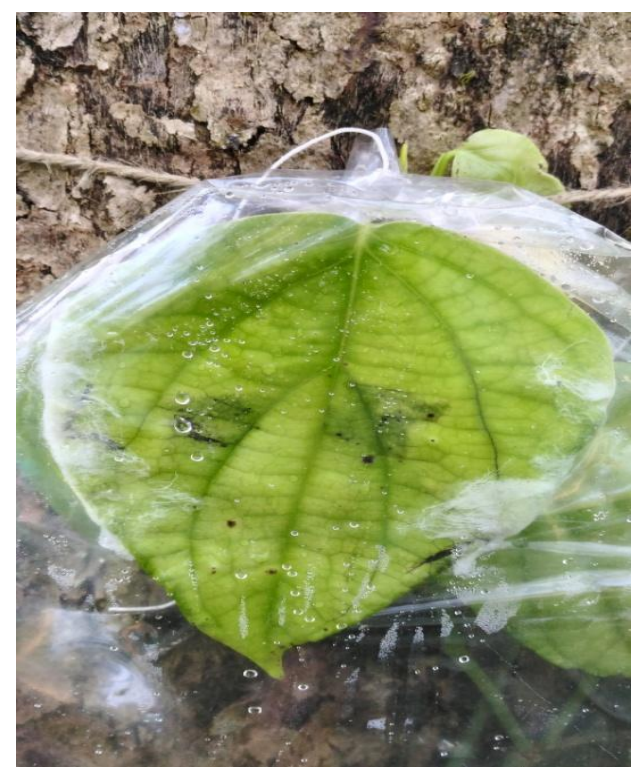

Fig.7 Water soaked lesions

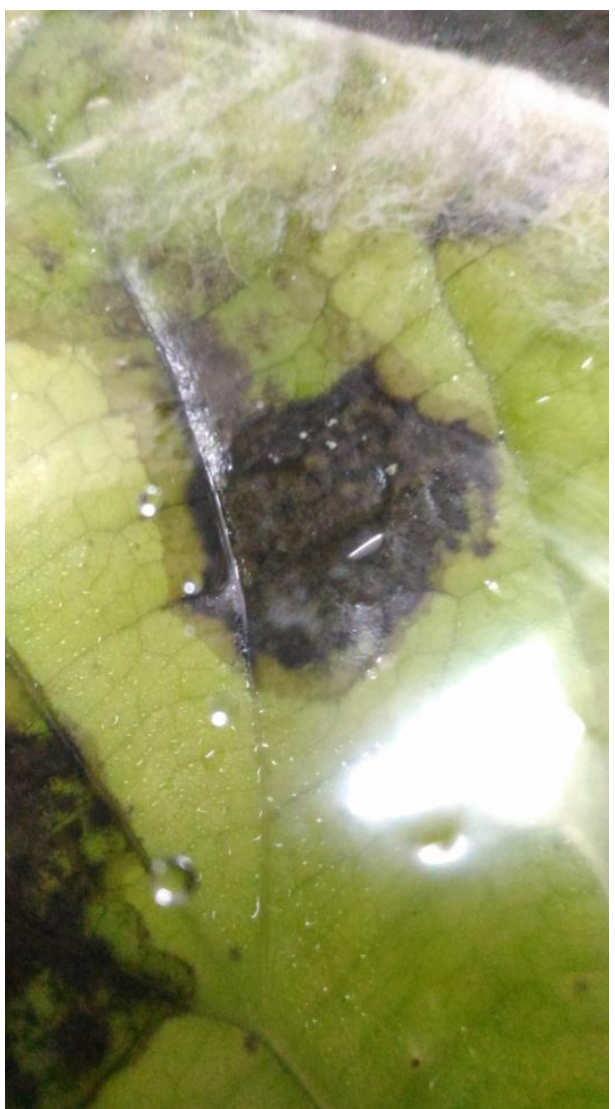

Fig.8 Greyish dark brown lesions 
Int.J.Curr.Microbiol.App.Sci (2019) 8(5): 2245-2254

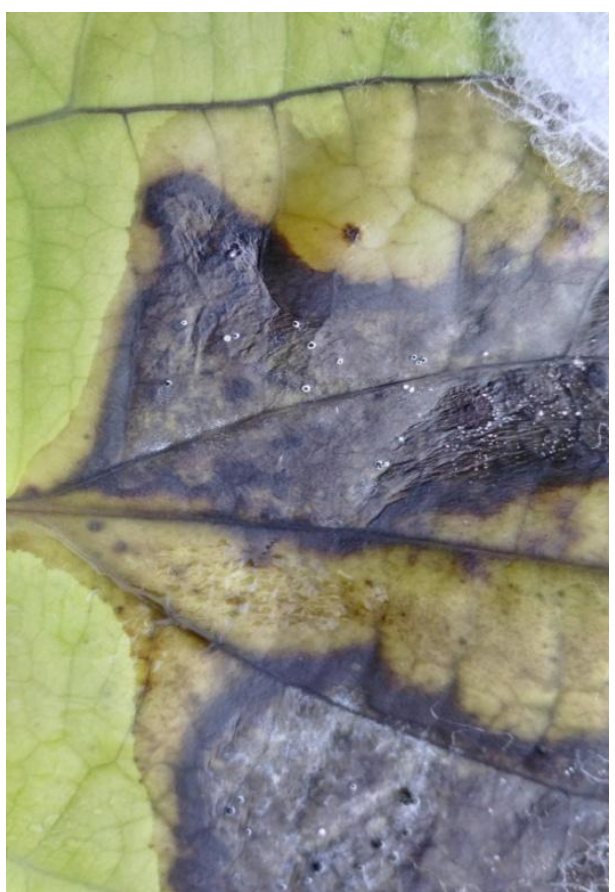

Fig.9 Sporodochia on the inoculated area

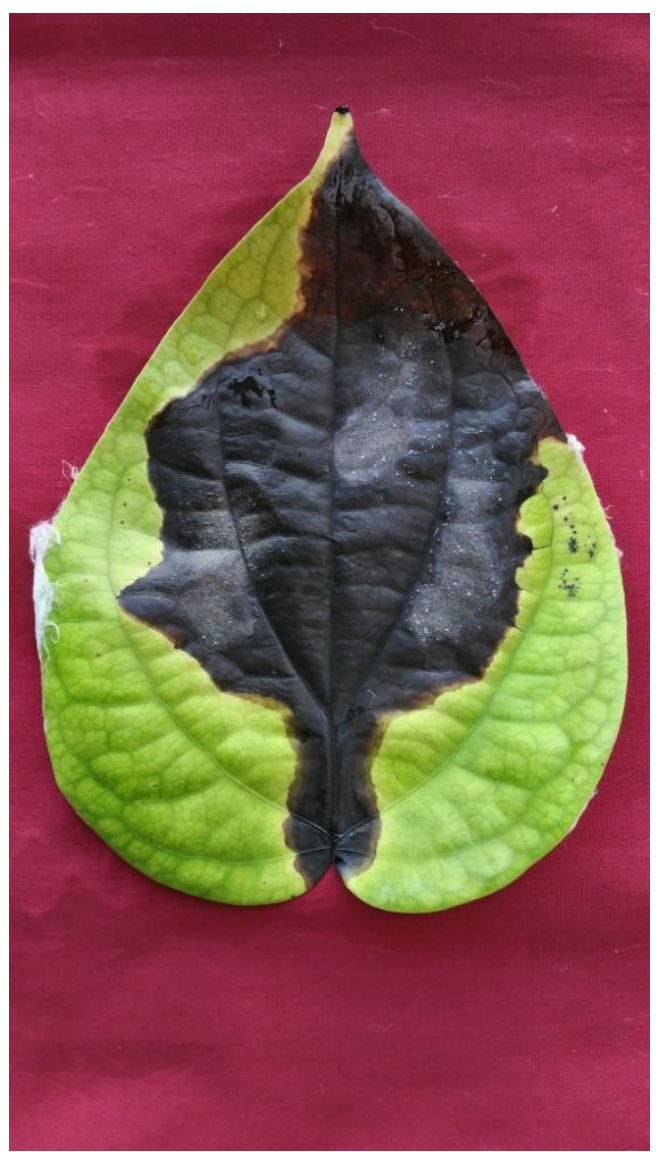

Fig.10 Detached pepper Leaf 


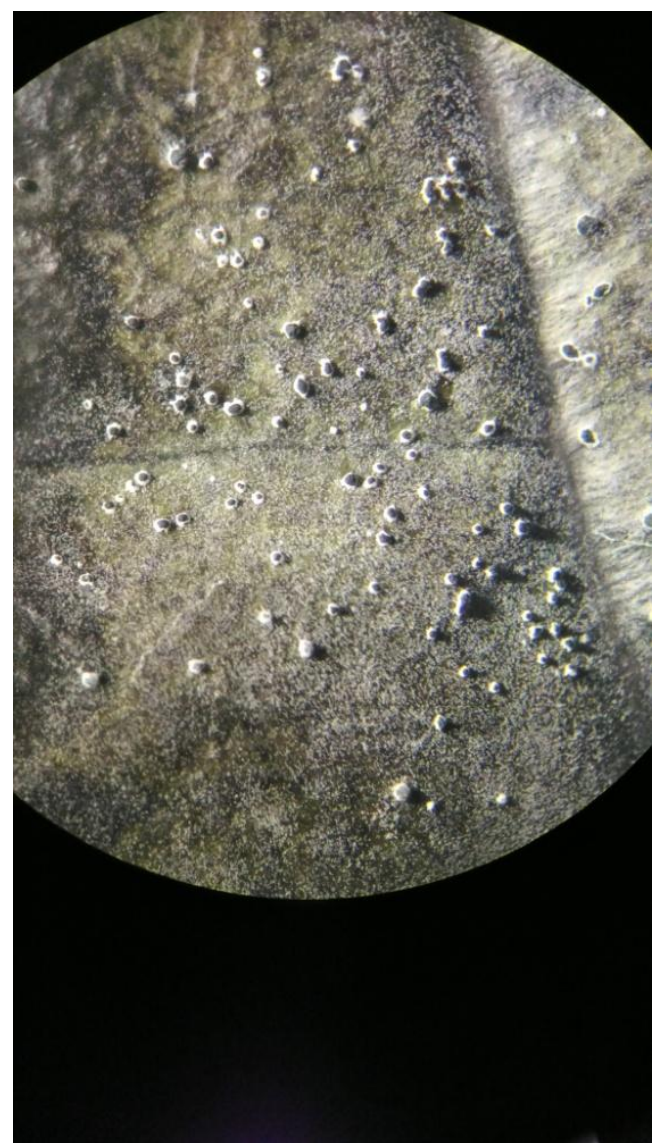

Fig.11 Microscopic view of sprodochia on pepper leaf

Jordan et al., (2018) confirmed the pathogenicity of $M$. roridum on pepper (Capsicum annuum) in United States and reported that $25{ }^{\circ} \mathrm{C}$ temperature and $75 \%$ relative humidity were favorable for the development of disease. Chase and Poole (1984) found that $21{ }^{\circ} \mathrm{C}$ to $27{ }^{\circ} \mathrm{C}$ was optimum for disease development in Dieffenbachia maculate and temperatures of $30{ }^{\circ} \mathrm{C}$ or higher inhibited lesion formation by $M$. roridum. Although most inoculation studies have used temperatures in the range of $25{ }^{\circ} \mathrm{C}$, Fitton and Holliday (1970) reported that optimum temperature for conidial germination by $M$. roridum is $28{ }^{\circ} \mathrm{C}$ and relative humidity is also another important requirement for infection and disease development. Singh et al., (2003) observed the maximum disease intensity of $M$. roridum in the first fortnight of September $(45.6 \%)$ when the average atmospheric temperature, relative humidity and rain were $27^{\circ} \mathrm{C}, 84.7 \%$ and $11.4 \mathrm{~mm}$ respectively. Tomar (2008) reported that the favourable climatic conditions for the development of Myrothecium blight in cotton includes a mean air temperature between $24.5^{\circ} \mathrm{C}$ and $28.8^{\circ} \mathrm{C}$, relative humidity between 45 to $69 \%$ and cumulative rainfall in the range of 251 to 522 $\mathrm{mm}$. There is report that based on the pathogenicity of $M$. roridum on the weeds, it could also be used as a bio-herbicide.

The present study revealed that the fungus $M$. roridum isolated from the leaves of coffee seedlings and field plants could infect the leaves of pepper vines and vice-versa indicating the virulence and potential of the pathogen. As black pepper (Piper nigrum L.) is a major intercrop grown in most of the coffee plantations of India, it is important to monitor the incidence of Myrothecium disease 
not only on coffee but also on pepper particularly during continuous rain to keep the pathogen at bay and to take up appropriate control measures so as to realize maximum crop.

\section{Acknowledgement}

The authors wish to thank the Director of Research, Central Coffee Research Institute (CCRI), Balehonnur for providing the required facilities to carry out the studies.

\section{References}

Aneja, K. R. 2012. Experiments in Microbiology, Plant Pathology and Biotechnology. New New Age International (P) limited, New Delhi. 607 pp.

Age International (P) limited, New Delhi. 607 pp.

Anonymous. 2014. Coffee Guide - A Manual of Coffee Cultivation. Published by Coffee Board of India. 262 pp.

Anonymous. 2018. Data base on coffee. Market Research and Intelligence Unit. Published by Coffee Board of India. $120 \mathrm{pp}$.

Chase, A. R. and Poole, R. T. 1984. "Development of Myrothecium Leaf Spot of Dieffenbachia maculate 'Perfection' at Various Temperatures". Plant Disease. 68 (6): 488-490.

Daivasikamani, S., Ranjini, A. P. and Raghuramulu, Y. 2016. Diseases of Coffee and their management. In: Plant Pathogens and their management. (Ed). Trivedi, P. C., Avaishkar Publishers, Distributors, Jaipur, Rajasthan, India. pp. 19-50.

French, A. M. 1989. California plant disease host index. Sacramento: California Department of Food and Agriculture.

Fitton, M. and Holliday, P. 1970. CMI Descriptions of pathogenic fungi and bacteria. No.253, Common wealth Mycological Institute (CMI), Ferry Lane, Kew, Surrey, England, UK.

Jordan, B., Culbreath, A. K., Brock, J and Dutta, B. 2018. First Report of Myrothecium leaf spot caused by Myrothecium roridum on Pepper in the United States. Plant Disease. 102(1): 246.

Kim, D. K., Bae, D. W., Lee, S. C., Han, K. S. and Kim, H. K. 2003. Detection of Myrothecium leaf spot, a new disease of watermelon. Plant Pathol. J. 19: 200202.

Kyung, S. H., Seung, K. C., Hyeong, H. K., Sung, C. 1., Jong, H. P., Myoung, R. C. and Mi-Jeong, P. 2014. First Report of Myrothecium roridum causing leaf and stem rot disease on Pepromia quandrangularis Korea. Mycobiology. 42: 203-205.

Mangandi, J. A., Seijo, T. E. and Peres, N. A. 2007. "First Report of Myrothecium roridum Causing Myrothecium Leaf Spot on Salvia spp. in the United States". Plant Disease. 91(6): 772.

Mc Lean, D. M. and Sleeth, B. 1961. "Myrothecium Rind Rot of Cantaloupe". Plant Disease Reporter. 45(9): 728-729.

Nagraj, T. R. and George, K. V. 1958. Target leaf spot disease of coffee: Occurrence symptoms and etiology. Indian Phytopathology. 11: 153-158.

Nirmala Kannan and Muthappa, B. N. 1982. Tip blight disease of young coffee plants in the nursery. J. Coffee Res. 12: $38-41$.

Preston, N. C. 1935. The parasitism of Myrothecium roridum Tode. Trans. Brit. Mycol. Soc. 20: 242-25.

Ranjini, A. P. and Raja Naika. 2018. Leaf spot and stem necrosis disease of coffee seedlings caused by Myrothecium roridum Tode ex Fr. in India. $J$. Mycopathol. Res. 56(1): 5-10. 
Schier, E. and Zentmyer, G. A. 1968. Myrothecium stem necrosis and leaf spot-important coffee disease in Guatemala. Plant Disease Reporter, 52: 115-117.

Silva, A. D. A. and Pinto D. B. 2016. First Report of leaf spot caused by Myrothecium. roridum on Coffea Canephora in Brazil. Plant Disease 98: 1587.

Silvado, F. S., Vinsente, M. D., Elaine, C. P., Pedro, P. D. 2007. Myrothecium leaf spot on coffee plants in nursery. Brazilian Phytopathology. 35: 440.

Singh, B. K., Singh, J., Narain, U. 2003. Role of environmental factors for development of Myrothecium leaf spot of pigeon pea. Annals Pl. Prot. Sci. 11(2): 401-402.

Tomar, D.S. 2008. Relationship between Myrothecium leaf blight of cotton and weather conditions. J. Mycol. Pl. Pathol. 38(3): 568-570.

Worapong, J., Sun, J and Newcombe, G. 2009. "First Report of Myrothecium roridum from a Gymnosperm". North American Fungi. 4(6): 1-6.

Wrigley, G. 1988. Coffee. Longman Scientific and Technical Co. Publications. England. pp. 639.

Yum, K. J., Park, E. W. 1990. Soybean leafspot disease caused by Myrothecium roridum Tode ex Fries. Korean J. Plant Pathol. 6: 313-317.

\section{How to cite this article:}

Ranjini, A.P., Madhu S. Giri, S. Daivasikamani, Santoshreddy Machenahalli, M. Sudha and Rajanaika. 2019. First Report on Cross-Infection of Coffee Leaf Spot Pathogen Myrothecium roridum on Black Pepper. Int.J.Curr.Microbiol.App.Sci. 8(05): 2245-2254.

doi: https://doi.org/10.20546/ijcmas.2019.805.264 